\title{
Thermal Energy Storage Configurations for Small Modular Reactor Load Shedding
}

Konor Frick, Corey T. Misenheimer, Dr. J. Michael Doster, Dr. Stephen D. Terry

March 2018

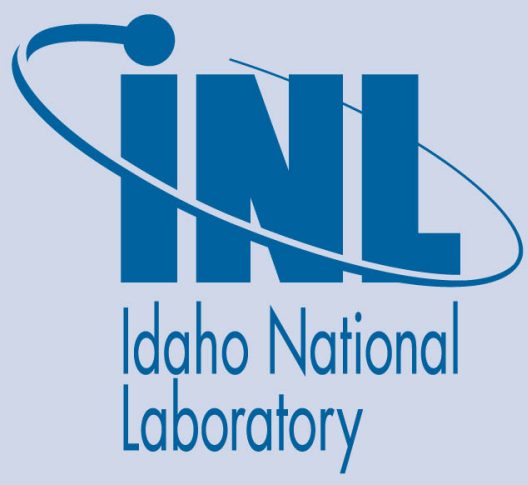

The INL is a U.S. Department of Energy National Laboratory operated by Battelle Energy Alliance 


\section{Thermal Energy Storage Configurations for Small Modular Reactor Load Shedding}

Konor Frick, Corey T. Misenheimer, Dr. J. Michael Doster, Dr. Stephen D. Terry

March 2018

Idaho National Laboratory Idaho Falls, Idaho 83415

http://www.inl.gov

Prepared for the U.S. Department of Energy Office of Nuclear Energy Under DOE Idaho Operations Office

Contract DE-AC07-05ID14517 
Title: Thermal Energy Storage Configurations for Small Modular Reactor Load Shedding

Article Type: Original Research Paper

Authors: Konor Frick ${ }^{\mathrm{a} *}$, Corey T. Misenheimer ${ }^{\mathrm{b}}$, Dr. J. Michael Doster ${ }^{\mathrm{a}}$, Dr. Stephen D. Terry ${ }^{\mathrm{b}}$, Dr. Shannon Bragg-Sitton ${ }^{\mathrm{c}}$

${ }^{a}$ Department of Nuclear Engineering, North Carolina State University, 2500 Stinson Drive, 3105

Burlington Engineering Labs, Raleigh, NC, 27695-7909

${ }^{b}$ Department of Mechanical and Aerospace Engineering, North Carolina State University, 911 Oval Drive, Box 7910, NCSU Campus, Raleigh, NC, 27695, USA.

${ }^{\mathrm{c} S y s t e m s ~ I n t e g r a t i o n ~ D e p a r t m e n t, ~ I d a h o ~ N a t i o n a l ~ L a b o r a t o r y ~}$

*Corresponding Author, Email: klfrick2@ncsu.edu, Phone: 919.270.2791

Total number of Pages : 34

Total number of Tables : 4

Total number of Figures : 33

Send proofs and page charge invoice to: Konor Frick email: klfrick2@ncsu.edu

Address: Department of Nuclear Engineering, North Carolina State University, 2500 Stinson Drive, 3105 Burlington Engineering Labs, Raleigh, NC, 27695-7909 


\begin{abstract}
The increased penetration of intermittent renewable energy technologies such as wind and solar power can strain electric grids, forcing carbon-based and nuclear sources of energy to operate in a load follow mode. For nuclear reactors, load follow operation can be undesirable due to the associated thermal and mechanical stresses placed on the fuel and other reactor components. Various methods of Thermal Energy Storage (TES) can be coupled to nuclear (or renewable) power sources to help absorb grid variability caused by daily load demand changes and renewable intermittency. Two TES techniques are investigated as candidate thermal reservoirs to be used in conjunction with a Small Modular Reactor (SMR): a two-tank sensible heat storage system and a stratified chilled-water storage system. The goal when coupling the two systems to the SMR is to match turbine output and demand and bypass steam to the TES systems to maintain reactor power at approximately $100 \%$. Simulations of Integral Pressurized Water Reactor (IPWR) dynamics are run in a high-fidelity FORTRAN model developed at NCSU. Both TES systems are developed as callable FORTRAN subroutines to model the time-varying behavior associated with different configurations of these systems when connected to the SMR simulator. Simulation results reveal the sensible heat storage system is capable of meeting turbine demand and maintaining reactor power constant, while providing enough steam to power four absorption chillers for chilled-water production and storage. The stored chilled water is used to supplement cooling loads of an adjacent facility.
\end{abstract}

Keywords: TES, SMR, IPWR 


\section{Introduction}

Approximately $19 \%$ of the electricity produced in the United States comes from nuclear power plants [1]. Traditionally, nuclear power plants, as well as larger coal-fired plants, operate in a baseload manner at or near steady-state for prolonged periods of time. Smaller, more maneuverable plants, such as gas-fired plants, are dispatched to match electricity supply and demand above the capacity of the baseload plants. However, air quality concerns and mounting evidence of climate change has made the burning of fossil fuels less desirable, despite the current low costs of natural gas. Wind and solar photovoltaic (PV) power generation are attractive options due to their lack of carbon footprint and continued drop in cost. Yet, these renewable energy sources suffer from inherent intermittency. Solar PV cannot produce power at night and experiences plant capacity reductions during times of cloud cover, while wind farms are reliant on fluctuating airstreams. As a result, sudden changes in weather conditions can make it difficult for electrical utilities to match electricity supply and demand. This problem becomes more pronounced with increased renewable energy penetration into electric grids.

These problems with renewable power generation combined with environmental concerns have led to a renewed interest in power generation via nuclear energy. Specifically, various nuclear vendors have proposed and begun development of innovative Small Modular Reactor (SMRs) designs that can be manufactured at a single facility and transported to diverse sites. SMRs offer increased site compatibility, advanced passive safety systems for the removal of decay heat, lower capital costs for construction, and reduced primary and secondary-side inventory [2]. With a nominal electrical output of $300 \mathrm{MWe}$ or less, SMRs can be clustered in a single location to form a more traditional baseload nuclear power plant, or deployed to remote locations, such as military bases with limited grid access, to provide reliable emissions-free energy [3]. Furthermore, SMRs could replace traditional fossil fuel boilers in manufacturing plants that require combined heat and power (CHP).

The deployment of SMRs at off grid locations or on grids with high levels of intermittent renewable resources presents challenges to the system. Under these conditions, the reactor can be 
subjected to significant time varying electric loads. Options for accommodating this load have included operating nuclear reactors in a load follow mode, or operating the reactor at or near steady state and bypassing steam directly to the condenser [4]. Both of these strategies result in lost energy potential. Load follow operation can also result in additional stresses on the fuel and other mechanical components. A more attractive approach is to operate the reactor at or near steady state and bypass excess steam to a thermal energy storage system. The thermal energy can then be recovered, either as a supplement to the power plant during peak demand times, or used for other ancillary applications such as chilled-water production [5]. Sensible heat thermal energy storage systems have been demonstrated in solar energy systems [6]. This paper examines issues that occur when deploying SMRs subject to significant time varying electric loads and proposes two energy storage systems that help mitigate these issues.

\section{System Designs, Connections, and Control}

Integrated nuclear hybrid energy systems (NHES) involve the design and connection of several complex, standalone systems. The control algorithms involved are unique to each application and the particular design of the components. The hybrid energy systems described in this paper include an mPower [7] style SMR, sensible heat thermal energy storage system and a bank of absorption chillers coupled to a chilled-water storage tank.

\section{II.A. Reactor Simulator}

The target SMR in this work is an Integral Pressurized Water Reactor (IPWR) with operating parameters similar to those of the mPower reactor proposed by B\&W [7]. Operating parameters are given in Table I. IPWRs are characterized by having all major primary system components (core, steam generators, pressurizer, etc.) contained within the reactor vessel. A diagram of a typical IPWR is given in Figure 1. 


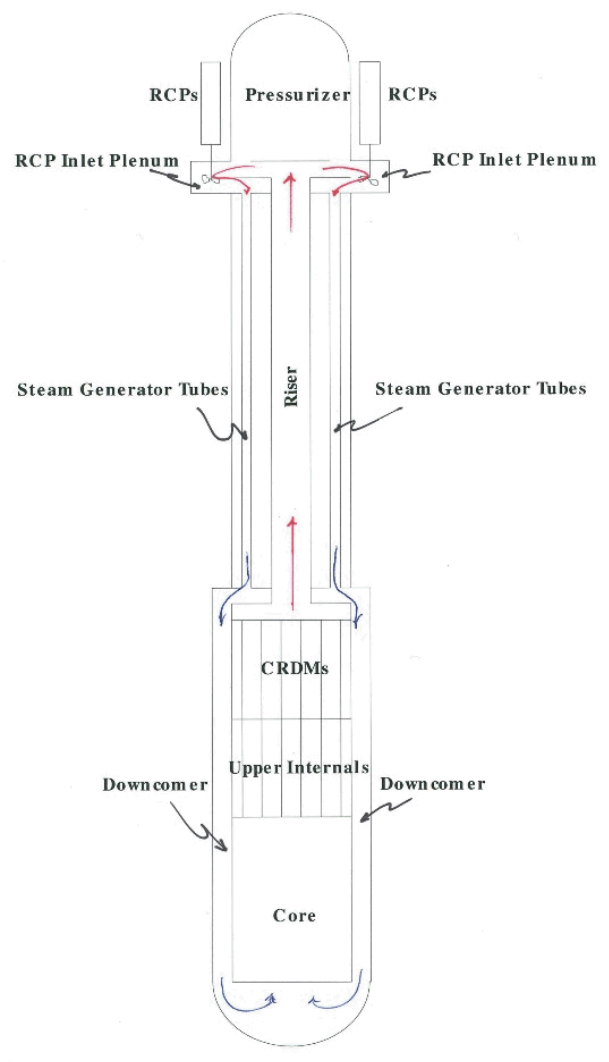

Figure 1: Representative Integral Pressurized Water Reactor

For the IPWR considered in this work the steam generators are a typical once through design, with steam generator pressure control via the turbine control valves (TCVs) located between the pressure equalization header and the high pressure turbine. Feed control valves modulate such that feed flow rate matches a feed demand signal that is proportional to the turbine load plus a shim that insures turbine output matches load. Steam generator level (boiling length) is allowed to float. In order to simulate the dynamics of an IPWR system, NCSU has developed high fidelity simulation tools for predicting the dynamic response of IPWR systems under normal and off-normal conditions [8-11]. The reactor simulator is capable of simulating IPWRs operating under forced and natural circulation conditions. A loop momentum balance approach is employed to compute the time dependent flow rates on the primary side. 
The time dependent energy equation is then discretized and solved to yield the fluid temperature distribution around the loop. Fuel temperatures are determined by discretizing and solving the 1-D time dependent heat conduction equation within the fuel rods. A three equation Drift Flux model is used to describe the secondary side of the steam generators [8]. Nodalization is up to the user, but typical of spatial discretizations used in reactor systems codes. Additional features include: a) A six group point kinetics model with overlapping control rod banks, Xenon, and fuel and moderator temperature feedback for computing reactor power, b) an eleven group decay heat model, c) hot channel models including Critical Heat Flux and peak fuel centerline temperatures, d) pressurizer with heaters and sprays, e) Balance of Plant and f) associated control functions. Since the nodalization is general, both conventional Once Through and Helical Coil Steam Generators can be simulated. The ordinary differential equations governing production and loss of Xenon and Iodine are solved in conjunction with the reactor kinetics model such that the power history dictates the Xenon concentration. Equilibrium Xenon worth is a user input. Typical LWR values were used in this work. As with other reactor systems codes, nodalization and geometric information are user specified such that models have been developed for IPWR concepts spanning a range of thermal outputs, including designs similar to the Westinghouse IRIS, B\&W, mPower, and NuScale reactor concepts [7].

Table I: SMR Operating Parameters

\begin{tabular}{|l|l|}
\hline Parameter & Value \\
\hline Reactor Thermal Output & $530 \mathrm{MWt}$ \\
\hline Electric Output & $180 \mathrm{MWe}$ \\
\hline Primary System Pressure & $14.134 \mathrm{MPa}(2050 \mathrm{psia})$ \\
\hline Core Inlet Temperature & $297^{\circ} \mathrm{C}\left(566^{\circ} \mathrm{F}\right)$ \\
\hline Core Exit Temperature & $322^{\circ} \mathrm{C}\left(611^{\circ} \mathrm{F}\right)$ \\
\hline Core Flow Rate & $13.6 \times 10^{6} \mathrm{~kg} / \mathrm{hr}(30 \mathrm{Mlbm} / \mathrm{hr})$ \\
\hline Steam Pressure & $5.68 \mathrm{MPa}(825 \mathrm{psia})$ \\
\hline Steam Temperature & $299{ }^{\circ} \mathrm{C}\left(571{ }^{\circ} \mathrm{F}\right)$ \\
\hline Feed Temperature & $212^{\circ} \mathrm{C}\left(414^{\circ} \mathrm{F}\right)$ \\
\hline Steam Flow Rate & $9.53 \times 10^{5} \mathrm{~kg} / \mathrm{hr} \quad(2.1 \mathrm{Mlbm} / \mathrm{hr})$ \\
\hline
\end{tabular}




\section{II.B. Sensible Heat Storage}

Sensible heat storage involves the heating of a solid or liquid without phase change and can be deconstructed into two operating modes: charging and discharging. A two tank thermal energy storage system is a common configuration for liquid sensible heat systems. In the charging mode cold fluid is pumped from a cold tank through an Intermediate Heat Exchanger (IHX), heated, and stored in a hot tank while the opposite occurs in the discharge mode. Such systems have been successfully demonstrated in the solar energy field as a load management strategy [6].

\section{II.B.1. Connection Point}

The performance of a Thermal Energy Storage (TES) System is a strong function of the connection point to the secondary side of the IPWR. For plants incorporating Once Through Steam Generators (OTSG) the turbine control valves (TCVs) acts as a pressure control valve to maintain Steam Generator pressure at a given set point. Shown in Figure 2 Turbine Bypass Valves (TBVs) can be configured such that bypass steam can either be taken off the steam line at the pressure equalization header upstream of the turbine control valves (Aux 1), downstream of the turbine control valves prior to entering the high pressure turbine (Aux 2), or at some low pressure turbine tap (Aux 3). For the sensible heat TES system assumed here, it is desired to have roughly constant steam conditions since the shell side pressure in the Intermediate Heat Exchanger directly affects the TES fluid temperature leaving the IHX and ultimately stored in the hot tank. This makes taking bypass steam from the pressure equalization header upstream of the turbine control valves the preferred operating mode. Steam conditions downstream of the TCVs are a strong function of the load profile. Taking bypass steam downstream of the turbine control valves can result in highly varying steam pressures and temperatures and unacceptably low IHX pressures. 


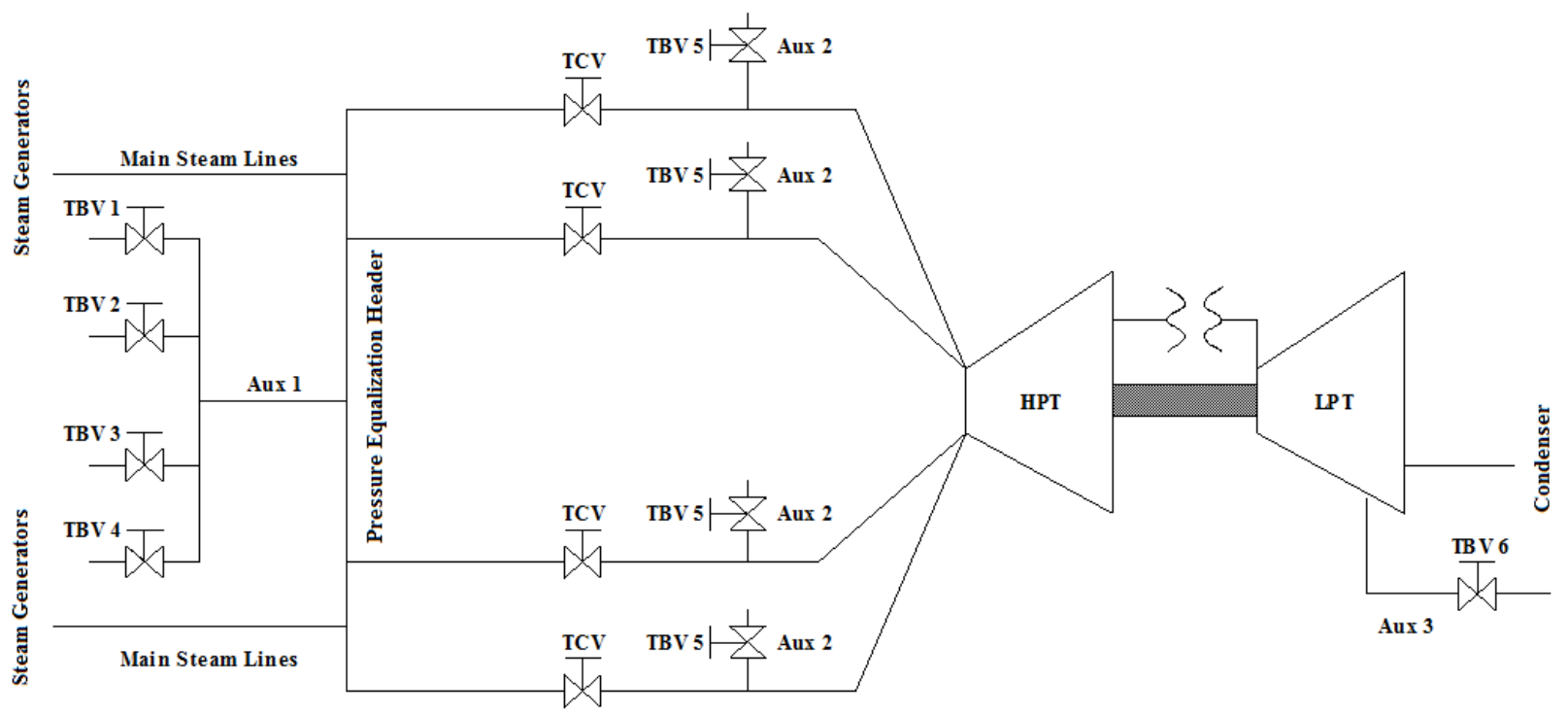

Figure 2: Bypass Steam Options

\section{II.B.2. Design}

The charging mode configuration of the proposed Thermal Energy Storage System is shown in the boxed region of Figure 3. An outer loop interfaces with the reactor's Balance of Plant (BOP) directly through four parallel auxiliary turbine bypass valves connected at the pressure equalization header, each staged to open at a certain percent of the maximum auxiliary flow demand. Bypass steam is directed through an intermediate heat exchanger (IHX) and discharged to the main condenser. An inner loop containing a TES fluid consists of two large storage tanks along with several pumps to transport the TES fluid between the tanks, the IHX and a steam generator. Flow Bypass Valves are included in the discharge lines of both the Hot and Cold tanks to prevent deadheading the pumps when the Flow Control Valves are closed. Common TES fluid properties are given in Table II. Therminol-66 is chosen as the TES fluid in this work as it is readily available, can be pumped at low temperatures, and offers thermal stability over 
the range $\left(-3^{\circ} \mathrm{C}-343^{\circ} \mathrm{C}\right)$ which covers the anticipated operating range of the TES system $\left(203^{\circ} \mathrm{C}-260^{\circ} \mathrm{C}\right)$. Therminol-68 and Therminol-75 could also have been used. Molten salts, e.g. $48 \% \mathrm{NaNO}_{3}-52 \% \mathrm{KNO}_{3}$, were not considered as the anticipated operating temperatures fall below their $222 \mathrm{C}$ freezing temperature [12].

Table II: Properties of Possible TES fluids at 260 degrees Celsius (500 degrees Fahrenheit)

\begin{tabular}{|c|c|c|c|}
\hline Heat Transfer Fluid & Boiling Point $\left({ }^{\circ} \mathrm{C}\right)$ & Heat Storage $\left(\mathrm{W}^{*} \mathrm{hr} / \mathrm{m}^{3}{ }^{3} \mathrm{C}\right)$ & Operating Range $\left({ }^{\circ} \mathrm{C}\right)$ \\
\hline Therminol $₫-66$ [13] & $358(678 \mathrm{~F})$ & $1039\left(576.95 \mathrm{~W} * \mathrm{hr} / \mathrm{m}^{3} \circ \mathrm{F}\right)$ & -2.7 to $343.3(27 \mathrm{~F}$ to $650 \mathrm{~F})$ \\
\hline Therminol $₫-68$ [14] & $307(586 \mathrm{~F})$ & $1013\left(563.03 \mathrm{~W} * \mathrm{hr} / \mathrm{m}^{3} \circ \mathrm{F}\right)$ & -25.5 to $360(-14 \mathrm{~F}$ to $680 \mathrm{~F})$ \\
\hline Therminol ${ }^{\circledR}-75$ [15] & $342(649 \mathrm{~F})$ & $992\left(551.54 \mathrm{~W} * \mathrm{hr} / \mathrm{m}^{3} \circ \mathrm{F}\right)$ & 79.44 to $385(175 \mathrm{~F}$ to $725 \mathrm{~F})$ \\
\hline
\end{tabular}

The TES system is designed to allow the reactor to run continuously at $\sim 100 \%$ power over a wide range of operating conditions. System parameters for an mPower [7] size system are given in Table III. During periods of excess capacity, bypass steam is directed to the TES unit through the auxiliary bypass valves where it condenses on the shell side of the IHX. TES fluid is pumped from the Cold Tank to the Hot Tank through the tube side of the IHX at a rate sufficient to raise the temperature of the TES fluid to some set point. The TES fluid is then stored in the Hot Tank at constant temperature. Condensate is collected in a hot well below the IHX and drains back to the main condenser, or can be used for some other low pressure application such as chilled water production or desalination. Applications to chilled water production are considered in this paper. The system is discharged during periods of peak demand, or when process steam is desired, by pumping the TES fluid from the Hot Tank through a boiler (steam generator) to the Cold Tank. This process steam can then be reintroduced into the power conversion cycle for electricity production or directed to some other application through the Pressure Control Valve (PCV) at the exit of the steam dome. While the boiler in Figure 3 implies a Once Through Steam Generator (OTSG) design, a U-Tube design could just as easily be substituted. Pressure relief lines connect the shell side of the IHX with the condenser to prevent over pressurization of the heat exchanger during periods of low condensation rate. A nitrogen cover gas dictates the tank pressures during charging and discharging 
operation. For the purposes of this paper we will focus on the charging mode when deployed in conjunction with an IPWR system. In previous work, details on the equation sets and solution strategy used for solving the charging system have been provided [16].

Table III: TES Design Parameters for connection with an mPower size IPWR

\begin{tabular}{|l|l|}
\hline Parameter & Value \\
\hline TES Fluid & Therminol ${ }^{\circledR}-66$ \\
\hline Hot Tank Volume & $226,535 \mathrm{~m}^{3}$ \\
\hline Cold Tank Volume & $226,535 \mathrm{~m}^{3}$ \\
\hline IHX Reference Exit Temperature & $260{ }^{\circ} \mathrm{C}\left(500^{\circ} \mathrm{F}\right)$ \\
\hline Number of TBV's & 4 \\
\hline TES Maximum Steam Accommodation & $\sim 45 \%$ nominal steam flow \\
\hline Pressure Relief Valve Upper Setpoint & $5.377 \mathrm{MPa}(780 \mathrm{psia})$ \\
\hline Pressure Relief Valve Lower Setpoint & $5.240 \mathrm{MPa}(760 \mathrm{psia})$ \\
\hline Turbine Header Pressure & $5.688 \mathrm{MPa}(825 \mathrm{psia})$ \\
\hline Shell Side (outer loop) IHX Volume & $101.94 \mathrm{~m}^{3}\left(3600 \mathrm{ft}^{3}\right)$ \\
\hline Number of Tubes & 19140 \\
\hline Length of Tubes & $11.25 \mathrm{~m}(36.9 \mathrm{ft})$ \\
\hline Tube Inner Diameter & $0.013 \mathrm{~m}(0.044 \mathrm{ft})$ \\
\hline Tube Outer Diameter & $0.018 \mathrm{~m}(0.058 \mathrm{ft})$ \\
\hline
\end{tabular}




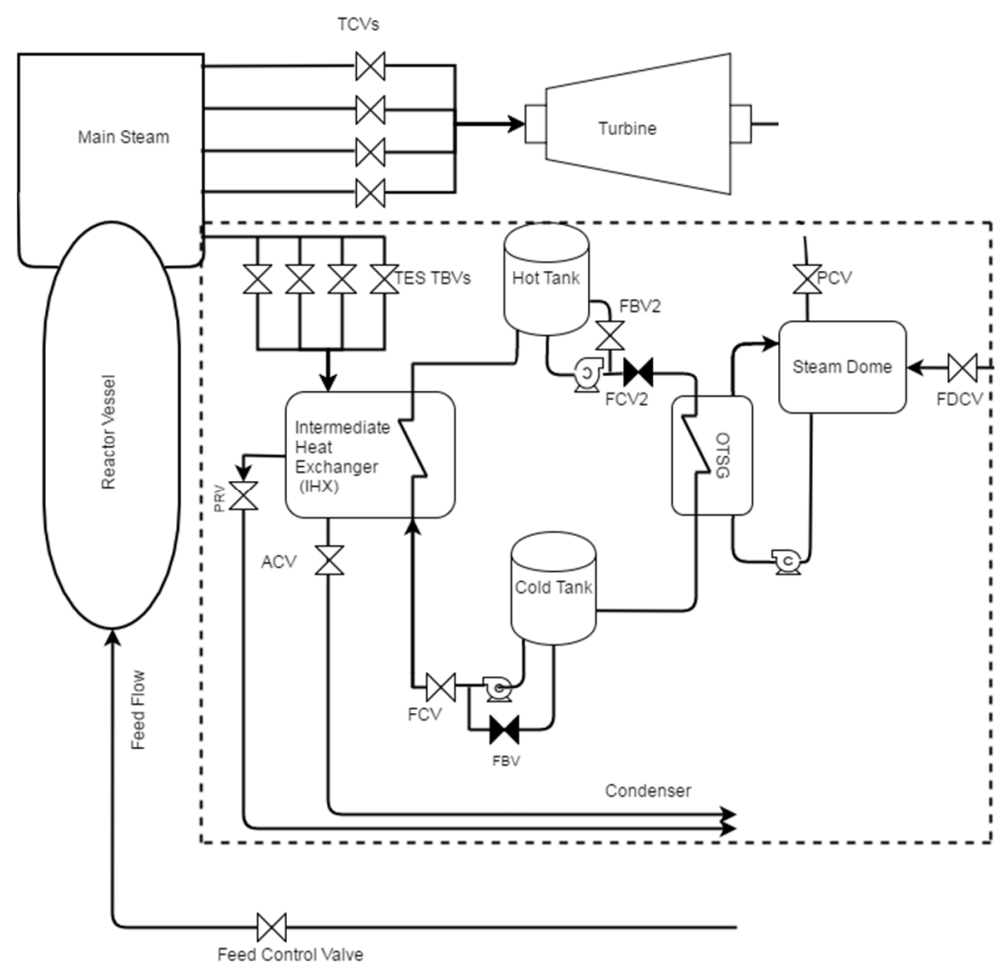

Figure 3: Schematic of an IPWR connected to a two-tank sensible heat thermal energy storage system, charging mode

\section{II.B.3. Control}

The TES system has four sets of valves used to control system parameters: auxiliary bypass valves, the TES flow control valve, the auxiliary control valve, and pressure relief valves.

The goal of the bypass flow controller is to provide bypass steam to the TES system at a rate sufficient to maintain the reactor at or near its nominal steady state value. The bypass valve controller generates an error signal based on the difference between measured bypass flow and a bypass flow demand signal. The bypass demand signal assumes the required bypass flow is proportional to the relative difference between the nominal full power turbine output and the instantaneous electric load plus a correction term (shim). The shim term modifies the demand signal such that reactor power is kept approximately constant. 
Flow from the cold tank to the hot tank is via a TES flow control valve. The TES flow control valve operates off a three element controller where the first error signal is designed to maintain the TES fluid temperature leaving the Intermediate Heat Exchanger at some reference value. The second error signal is designed to roughly match the heat input into the TES fluid with the heat bypassed to the IHX.

The auxiliary control valve (ACV) maintains IHX hot well level. This valve operates on a three element controller based on the level of the IHX and the difference in mass flows into and out of the IHX. Pressure relief valves (PRV's) have been installed in the IHX to mitigate pressure increases. Should pressure reach an upper set point the valves will open and will not close until the pressure falls below a lower set point. The only parameters directly controlled during charging mode operation of the TES system are the IHX exit temperature on the inner loop and the level in the IHX. All other variables including IHX pressure, tank levels, inner loop mass flow rate, and heat transfer across the IHX are determined from the mass, energy and momentum balances on the system.

A stop valve (not shown) is placed in the flow line between the cold tank and hot tank to ensure tank pressure and level stay below designated set points. Should either the pressure or level set points be exceeded the stop valve will close and TES fluid flow between the tanks will cease. A redundant control on level is that the volume of Therminol-66 in the system is less than the total volume of either tank.

\section{II.C. Chilled-Water Storage}

Chilled-water storage is often overlooked as an effective TES method. Chilled water is regularly used in large manufacturing facilities, college campuses, and district heating and cooling systems to satisfy cooling demands. Traditionally, electric chillers make chilled water via the vapor-compression cycle. The chilled water is pumped to air handlers throughout a facility to satisfy comfort cooling needs. During warmer months of the year, a large portion of a facility's electricity demand is generated from associated heating ventilation and air-conditioning (HVAC) equipment. Because building cooling loads regularly peak during the early to late afternoon hours, the HVAC equipment is sized to accommodate 
these peak loads. At night or during early morning hours when cooling loads are low, excess chiller capacity exists. Moreover, these peak facility cooling loads often coincide with peak electricity demands, thereby putting further strain on utilities. TES, in the form of chilled-water storage, is a way to combat peak cooling loads by shifting them from on-peak to off-peak hours [17].

Stratified chilled-water storage tanks have emerged as an effective option for storing chilled water [18]. In a stratified chilled-water storage tank, warm and cold water are stored in the same vessel with no solid component between the warm and cold volumes of water. Differences in density between cold and warm water cause a thin thermocline, or sharp temperature gradient, to form. Excess chilled water, produced when facility cooling demands are low, is deposited in the bottom of the tank via diffusers. Because the tank is a constant volume device, charging the tank with cold water means simultaneously removing warm water from the top of the tank to be sent to the chillers. Conversely, discharging the cold water to be used during times of peak facility cooling loads results in warm water being deposited in the top of the tank. Therefore, a fully charged tank implies the tank is full of chilled water, while a fully discharged tank implies the tank is full of warm water.

A previous case study examined using stratified chilled-water storage in conjunction with centrifugal electric chillers to offset cooling loads representative of a large office space or college campus in a NHES [19]. Results demonstrated that chilled-water storage can shift cooling loads to off-peak hours and help promote more steady-state reactor operation [19]. Another option for cooling water involves the use of single effect, lithium bromide absorption chillers, which use steam less than $205 \mathrm{kPa}$ (15 psig) or hot water and the affinity between an absorbent and a refrigerant to create a chilling effect. Absorption chillers become particularly attractive when a source of waste heat that would normally be rejected to the environment or some other low temperature sink is available. As illustrated in Figure 2, low-pressure steam can be diverted from a low-pressure turbine-tap to absorption chillers to make chilled water for storage when excess reactor capacity exists. 


\section{II.C.1. Mathematical Model Development}

Absorption chiller performance is highly dependent on the flow rates and temperatures associated with supplied steam, chilled water, and cooling tower water. Additionally, the substantial thermal mass in large absorption chillers results in long transients on the order of tens of minutes. In order to determine how an absorption chiller might interact with an SMR in a NHES, a dynamic absorption chiller model is required.

Although single effect, lithium bromide absorption chillers are complex machines, their numerous components can be reduced to four shell-and-tube heat exchangers, an intermediate heat exchanger, valves, and pumps [20]. The generator and condenser are housed in the upper shell, while the evaporator and the absorber are located in the lower shell. A dynamic absorption chiller model capable of accurately capturing heat transfer phenomena inside the chiller has been developed based on models available in literature [21-22]. The transient thermodynamic model is grounded on mass, energy, and species conservation equations in each of the four main heat exchangers. Appropriate heat transfer coefficients for various modes of heat transfer are included in the model [23-24]. Dobson and Chato's [25] model for heat transfer via condensation inside horizontal tubes that divides the condensation flow into annular, stratified-wavy, and stratified flow regimes, is used to determine local heat transfer coefficients inside generator tubes. An applicable two-phase flow multiplier correlation for pressure drop calculations enables steam temperature, quality, and pressure to be established along the generator tube bundle [26]. The inclusion of the in-tube condensation heat transfer model and two-phase flow pressure drop correlations to describe heat addition in the generator combined with the solving of the timedependent mass, species, and temperature transport equations in each chiller component sets the absorption chiller model described in this paper apart from every other absorption chiller model found throughout literature. In addition, the added fidelity in the generator of the absorption chiller model ensures accurate part-load chiller behavior as well as precise condensate conditions returning to reactor subsystems. Further information regarding the dynamic absorption chiller model's governing equations, 
heat transfer coefficient correlations, solution strategy, and validation is available in [27] and [28]. Cooling tower and stratified chilled-water storage tank models from previous studies are used to complete the comprehensive TES system [28].

\section{II.C.2. SMR Integration}

The transient absorption chiller model, along with time-dependent models of the cooling towers and stratified chilled-water storage tank, is converted to a callable FORTRAN subroutine. This allows the dynamic SMR model described earlier in this paper to call the chilled-water storage subroutine at each time-step during a simulation. Three absorption chillers are used in conjunction with a $18,927 \mathrm{~m}^{3}$ $(5,000,000$ gallon) stratified chilled-water storage tank in order to offset HVAC loads of an adjacent $92,903 \mathrm{~m}^{2}\left(1,000,000 \mathrm{ft}^{2}\right)$ office space. The goal of the control strategy when coupling the chillers to the SMR is to keep reactor thermal power output roughly constant and bypass low-pressure steam from the low-pressure turbine to absorption chillers during times of excess reactor capacity. Chilled-water produced during periods of excess reactor capacity is sent to the stratified chilled-water storage tank. Under nominal turbine loads, the extracted steam at the low-pressure turbine tap has a pressure of $297 \mathrm{kPa}$ (43 psia) and a quality of $85 \%$. One $4,843 \mathrm{~kW}(1,377$ nominal ton) absorption chiller requires $3.14 \mathrm{~kg} / \mathrm{s}$ $(25,000 \mathrm{lbm} / \mathrm{hr})$ of $165 \mathrm{kPa}$ (24 psia) steam to achieve full load. A TES Turbine Bypass Valve (TBV) and accompanying steam line are sized to accommodate approximately $9.45 \mathrm{~kg} / \mathrm{s}(75,000 \mathrm{lbm} / \mathrm{hr})$ of steam at nominal full loads. Condensed steam returning from the absorption chillers is sent back to the reactor condenser. A small condensate drain at the generator tube bundle exit and steam traps in the condensate lines leaving the absorption chiller necessitate that all steam sent to the absorption chillers is condensed. A maximum chilled-water temperature threshold for storage and satisfying facility cooling loads is established at a temperature of $7.2^{\circ} \mathrm{C}\left(45^{\circ} \mathrm{F}\right)$. In industry, chiller plants generally guarantee chilled water below $7.2^{\circ} \mathrm{C}$ to be sent to air handlers. Absorption chiller integration into the secondary side of the reactor is depicted in Figure 4. 


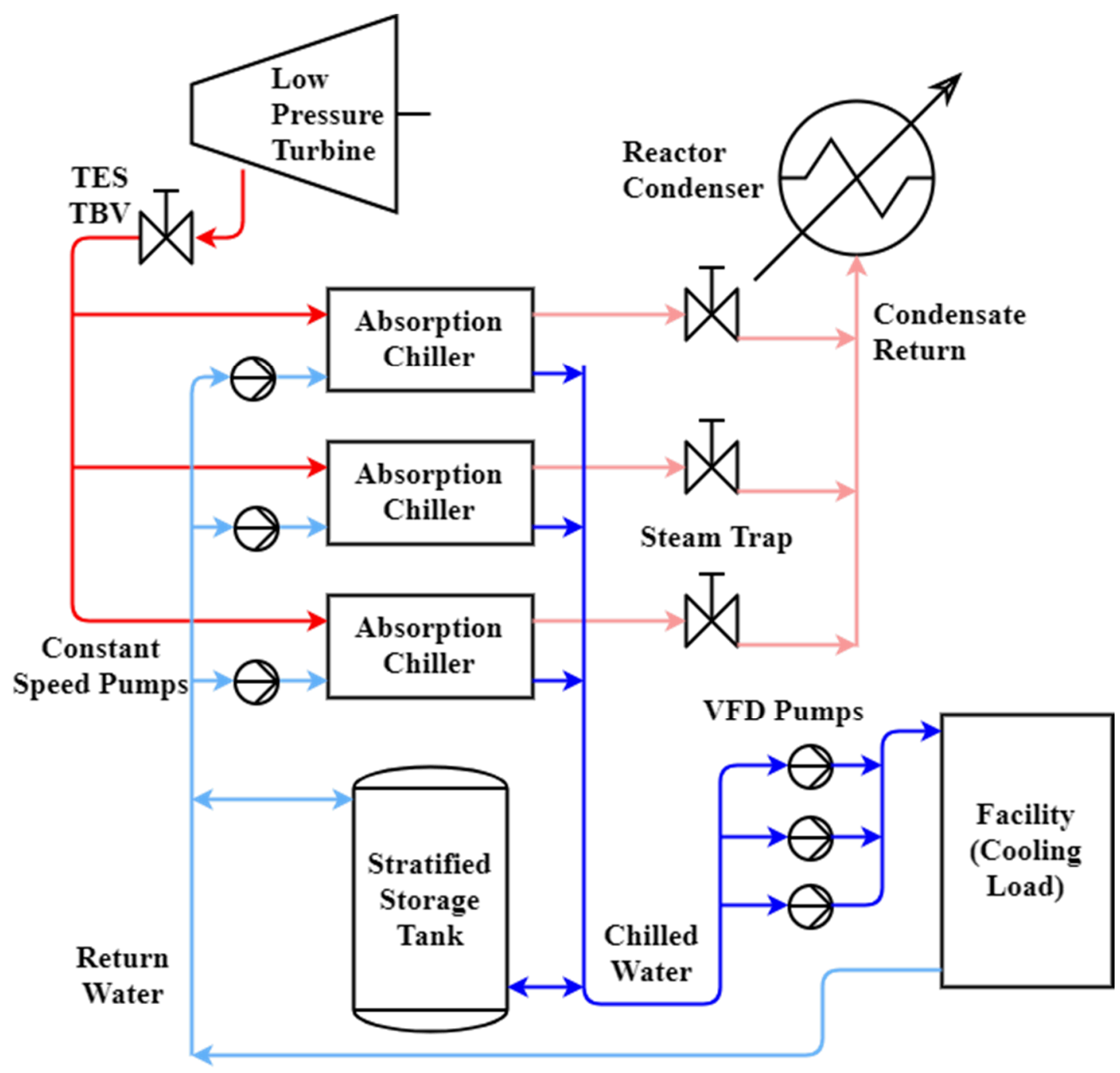

Figure 4: Absorption chiller SMR integration

\section{II.D. Flash Vessel Model}

An alternative to using steam from a low-pressure turbine tap is to couple the chilled-water storage system to the two tank TES system discussed earlier. Once the bypass steam has been condensed in the Intermediate Heat Exchanger it is no longer useful to the TES system, and would normally be directed to the condenser. However, for the system operating parameters assumed here, this condensate is sitting at a pressure of approximately $4.82 \mathrm{MPa}$ (700psia), making it high grade waste heat for other applications. To utilize this waste heat for low pressure applications such as chilled water production, the 
condensate from the IHX is dropped across a let-down orifice to produce a low pressure steam/water mixture. This two phase mixture is sent to a flash vessel where the liquid and vapor phases are separated. The saturated steam is then sent to an ancillary application to utilize the high grade waste heat byproduct produced in the TES system. A potential configuration for chilled water production is illustrated in Figure 5.

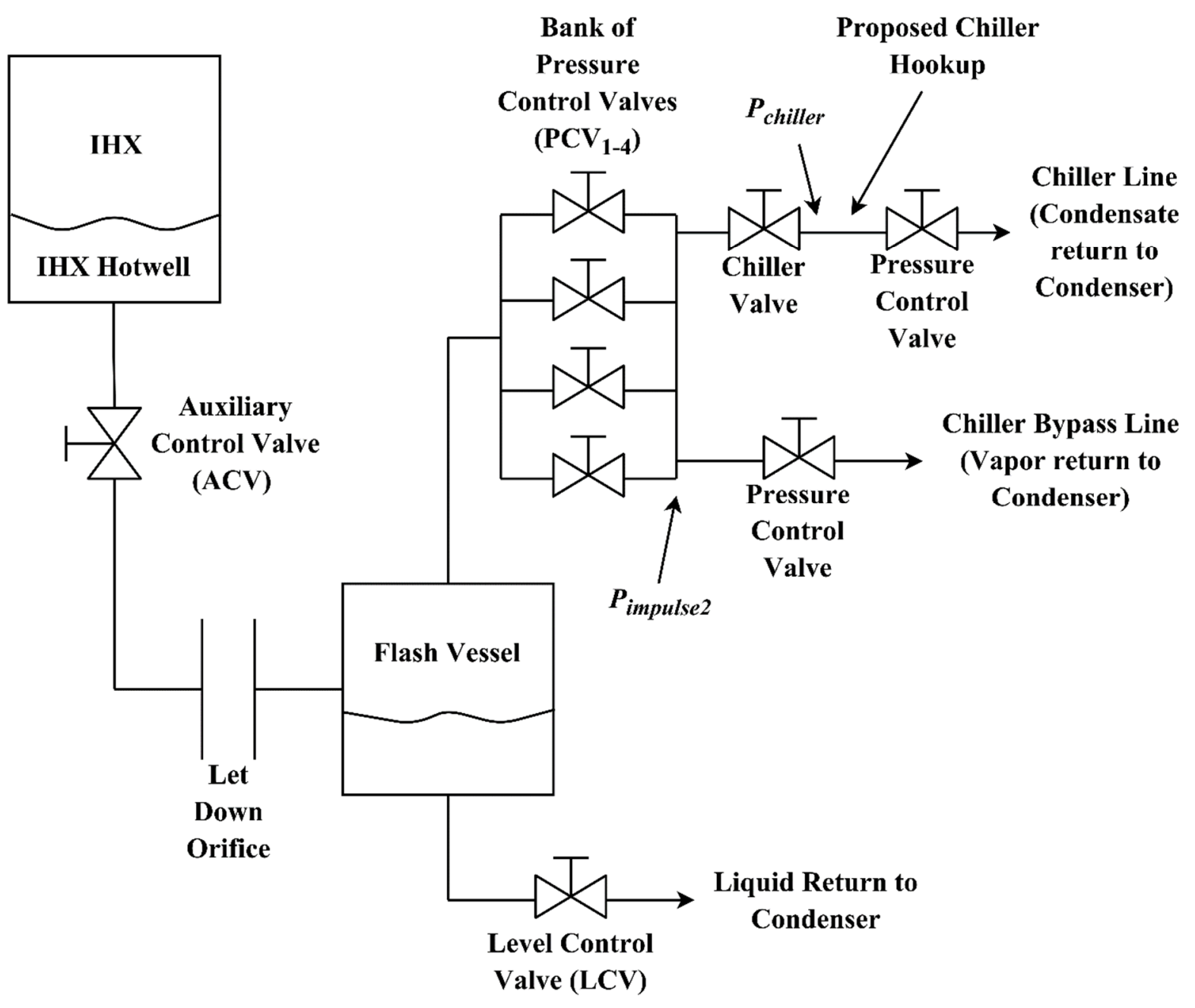

Figure 5: Flash vessel configuration

The Flash Vessel has six sets of valves used to control system parameters: the auxiliary control valve, level control valve, three sets of pressure control valves, and a chiller valve. The auxiliary control valve modulates to maintain level in the Intermediate Heat Exchanger. Thus during times of high bypass 
steam flow, there will be a corresponding high condensate flow exiting the IHX. The goal of the first bank of pressure control valves is to maintain the flash vessel at some user specified pressure. The second pressure control valve is located at the exit of the chiller line. This pressure control valve modulates to maintain a user specified pressure downstream of the chiller valve. The chiller valve operates on a binary signal such that if the thermocline level in the chiller is below some lower set point the valve goes to its full open position. Conversely when the thermocline level hits some upper set point the valve shuts. The third pressure control valve located on the bypass line around the chiller modulates to maintain a user defined pressure downstream of the main pressure control valve bank, this point is called $P_{\text {impulse } 2}$ in Figure 5. The level control valve, located at the bottom of the flash vessel maintains Flash Vessel level. This valve operates on a controller based on the level of the flash vessel and difference in mass flows into and out of the flash vessel. Parameters directly controlled in the flash vessel model are the flash vessel level, flash vessel pressure, pressure downstream of the first pressure control bank, and pressure downstream of the chiller valve.

\section{Results}

To compare several different modes of operation, a 24-hour simulation was run for an electric load profile representative of a typical summer day in an area with mixed commercial and residential characteristics [29]. A 24 hour cycle was chosen because it is the minimum amount of time required to show a full daily cycle for a region during a season. Week or month long runs will show the same general trends as the daily cycle with the only distinction being in tank level. The load profile has been scaled such that the minimum load is approximately $60 \%$ of nominal full power. Time zero corresponds to midnight.

\section{III.A. Load Follow Operation}

As a basis for comparison, the SMR is operated in Load Follow mode, where the reactor power is modulated to match the electric demand. As shown in Figures 6 and 7, the system is able to maneuver such that the turbine output is effectively identical to the electric demand, and the reactor power follows 
the load. For this simulation, a constant $\mathrm{T}_{\text {ave }}$ program was assumed with the corresponding control rod positions given in Figure 9. Four control banks are modeled. At the beginning of the maneuver, banks A-C are fully withdrawn, with D bank approximately 50\% inserted. Over the course of the maneuver bank D moves to its full out position, and by the end of the transient has returned to its approximate starting point. The average primary coolant temperature varies by 4 degrees Celsius over the course of the run as illustrated in Figure 10. The changes in core coolant temperatures, along with the changes in core power distribution and associated fuel temperatures add additional thermal stresses to the system, especially if repeated for multiple cycles. Figure 11 gives the variation in steam generator dryout location over the 24 hour run. Over the course of the run the dryout location varies by $15 \%$ of the tube length. The dryout location represents a sharp temperature gradient. Repeated cycling of this location can induce stresses that decrease the lifetime of the steam generator tubes. Of additional interest is the steam pressure downstream of the TCV (Turbine Impulse Pressure). As stated previously, steam conditions at this location are a strong function of the load profile and create additional challenges if connections to the TES system are made downstream of this point.

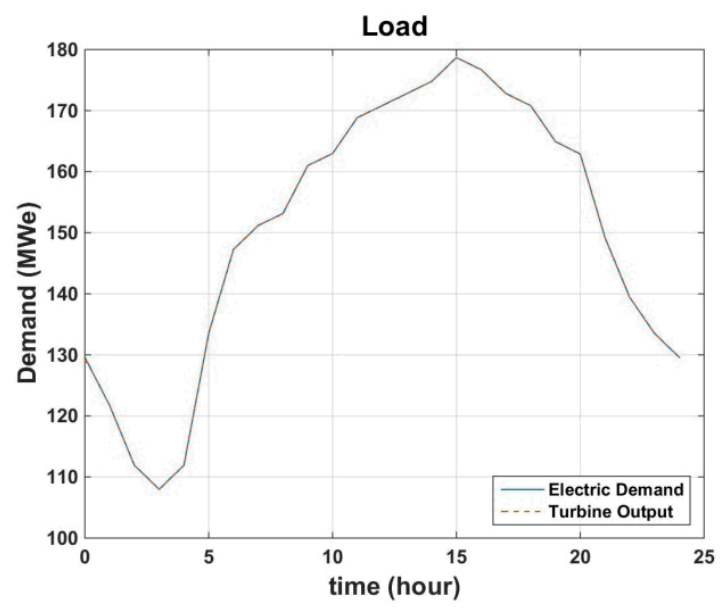

Figure 6: Turbine Output and Demand

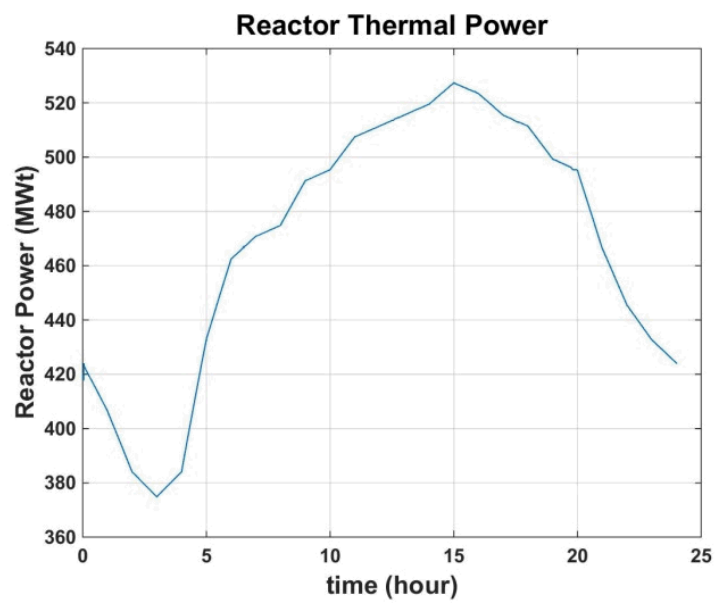

Figure 7: Reactor Power 


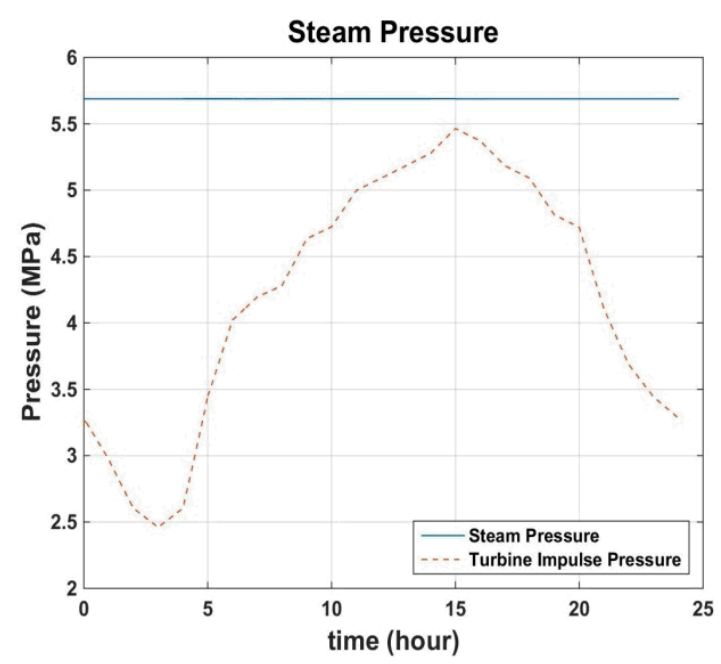

Figure 8: Steam Pressure

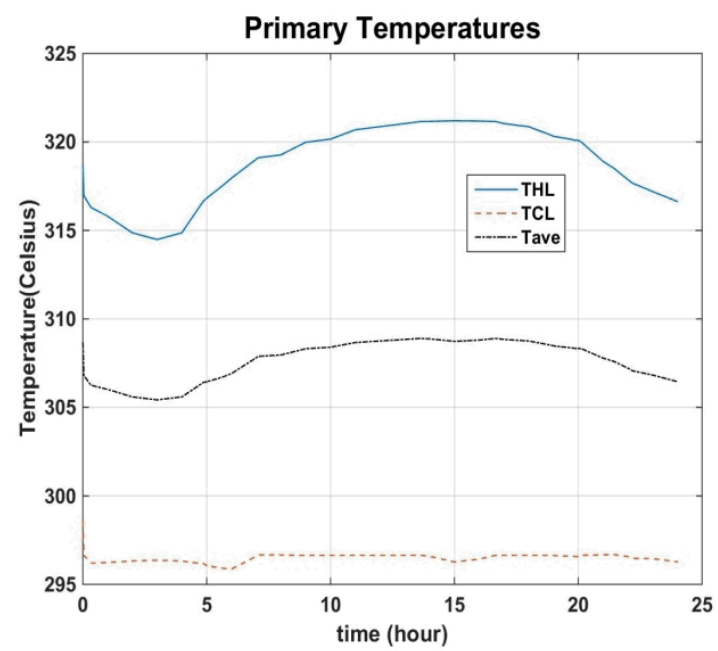

Figure 10: Primary Temperatures

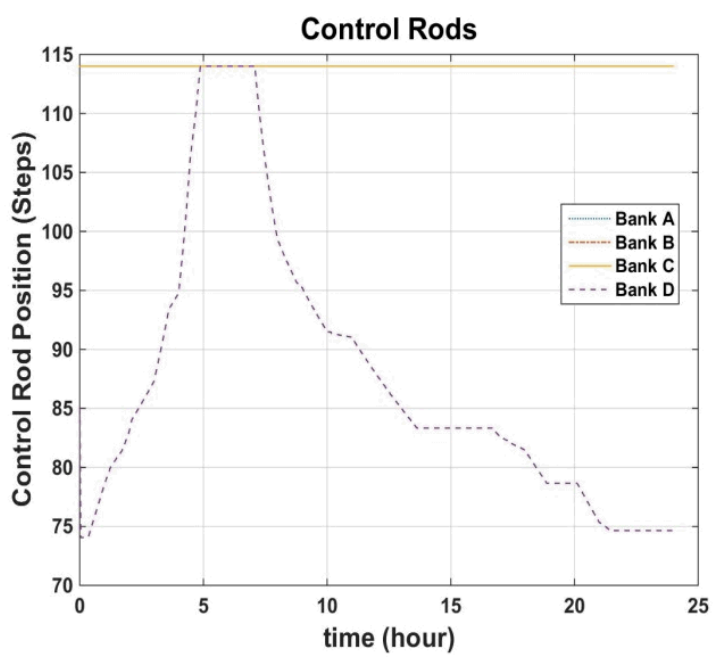

Figure 9: Control Rod Position

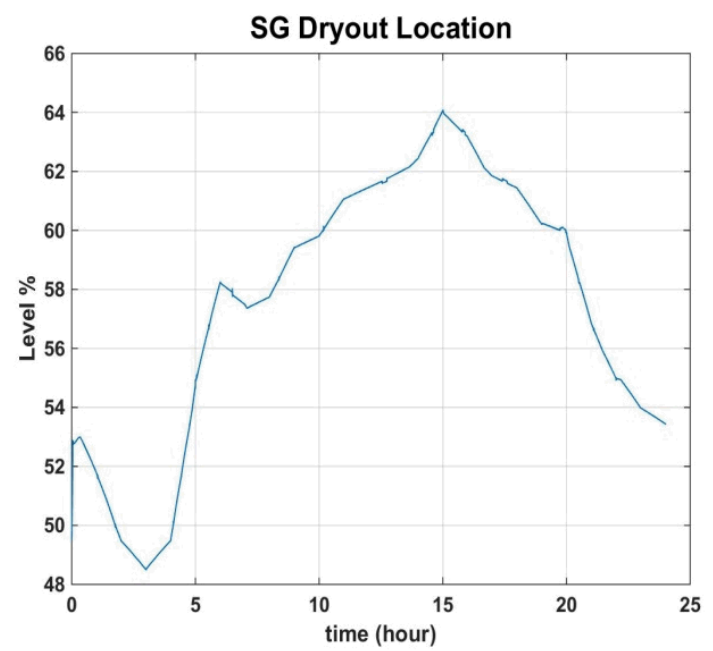

Figure 11: Steam Generator Dryout Location

\section{III.B. Reactor Coupled with TES storage system operation}

A 24 hour charging run was simulated with the TES system active. The same electric load profile as in the Load Follow case was assumed. As illustrated in Figures 12 and 13, the plant is able to maneuver such that the electric demand is satisfied while keeping reactor power effectively constant. As reactor power and reactor coolant temperatures were essentially constant, this maneuver could be 
executed without control rod movement and thermal stresses associated with changes in temperatures and power distributions have been effectively eliminated. The corresponding bypass flow to the TES system is shown in Figure 16. As would be expected, the bypass flow rate is essentially the inverse of the load profile. The steam generator dryout location varies by only $2 \%$ of the steam generator tube length for this simulation as compared with the $15 \%$ variation present during straight load follow. The TES fluid flow rate is shown in Figure 17 and closely follows the bypass flow rate. Steam generator and turbine impulse pressure are essentially unchanged from the Load Follow simulations.

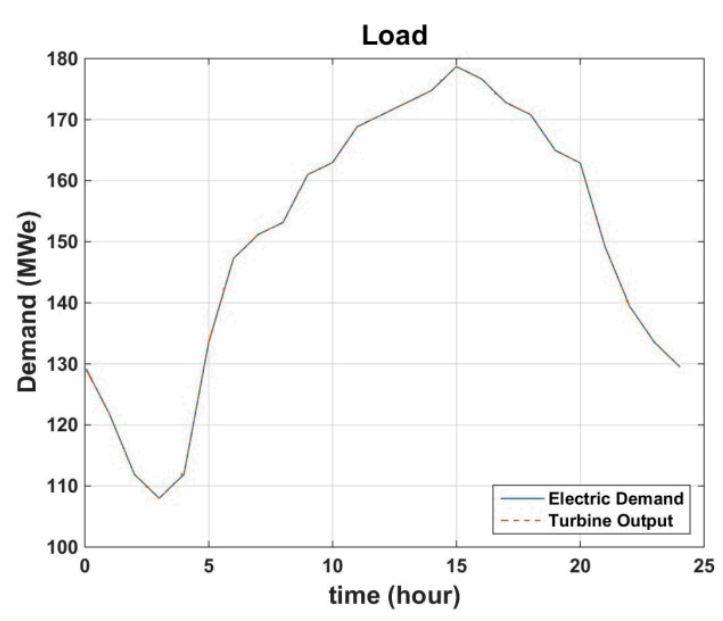

Figure 12: Turbine Output and Demand

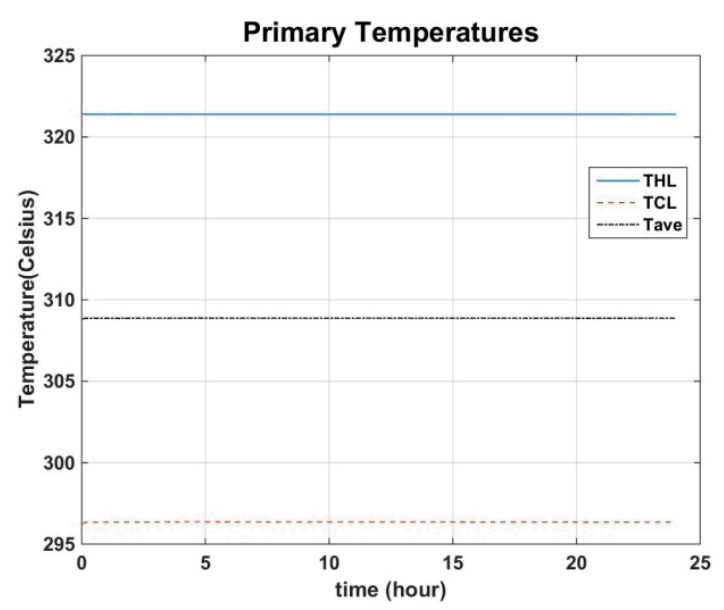

Figure 14: Primary Temperatures

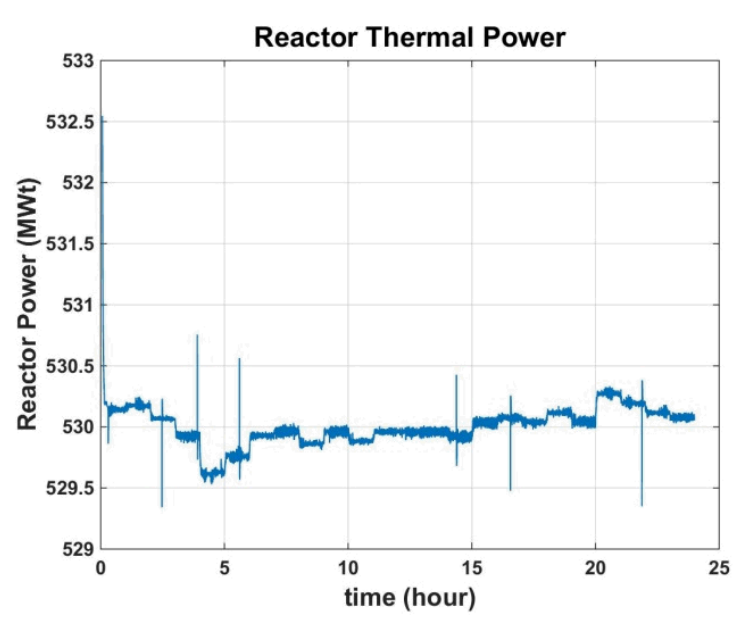

Figure 13: Reactor Power

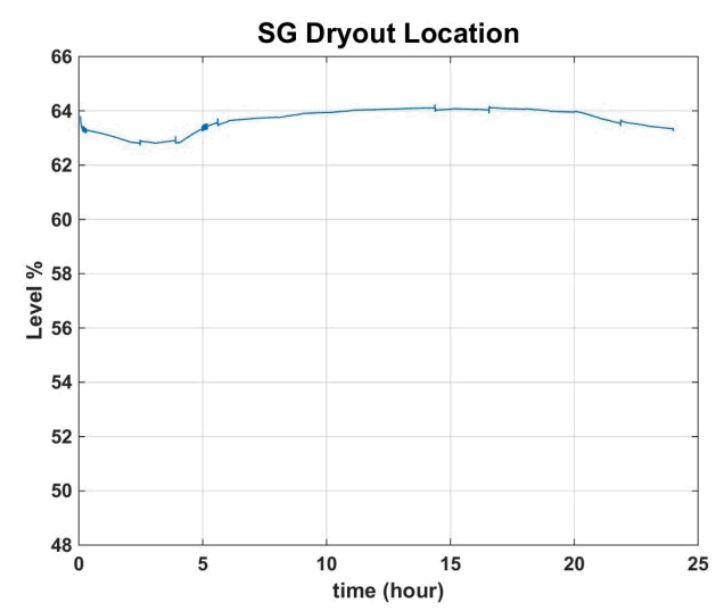

Figure 15: Steam Generator Dryout Location 


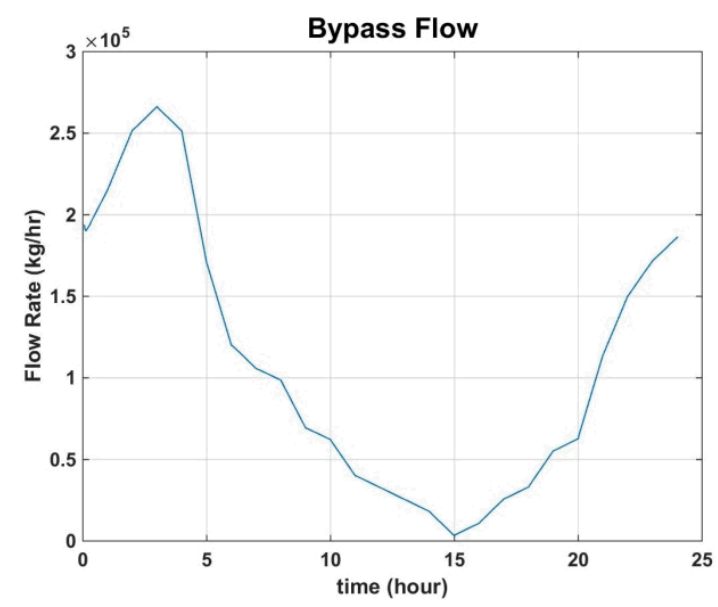

Figure 16: Bypass Flow into TES system

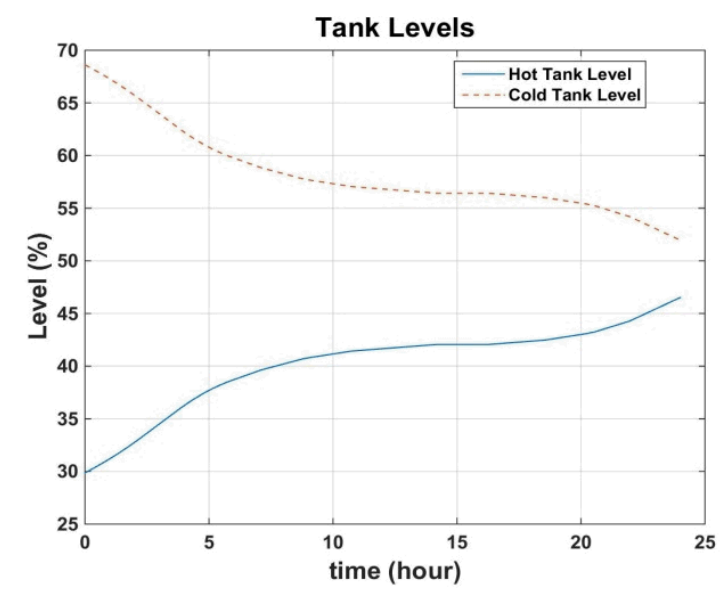

Figure 18: Hot and Cold Tank Levels

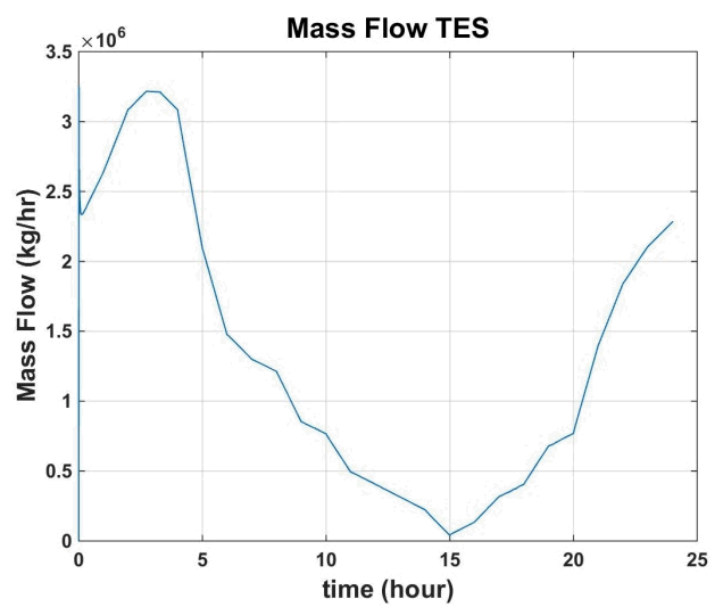

Figure 17: Flow of TES Fluid from Cold Tank to Hot Tank

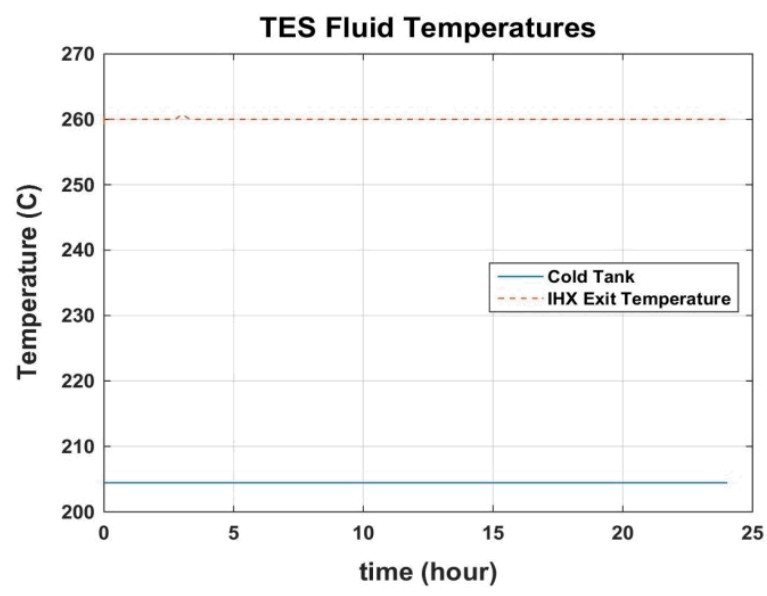

Figure 19: TES Temperatures

Figure 19 demonstrates that the flow controller for the TES flow control valve (FCV) is effective in keeping the IHX exit fluid temperature at its target value. The hot and cold storage tank levels are given in Figure 18. For the load profile considered here, the tanks have more than enough capacity to accommodate the excess thermal energy in the system. These results show that through the addition of a 
sensible heat TES system the reactor can be maintained at $\sim 100 \%$ power, thus keeping primary sides oscillations at a minimum.

\section{III.C. Reactor Coupled with TES storage system and intermittent renewables}

A further advantage of the TES system is the ability to accommodate the presence of intermittent energy sources on the grid, particularly solar energy generation that can vary depending on time of day or cloud cover. To illustrate these effects the load profile was modified to reflect upwards of 40MWe installed solar capacity as shown in Figure 20 and Figure 21. Over the course of the simulation, turbine load is met while thermal power stays approximately constant as illustrated in Figure 22 and Figure 23. The response of other system parameters is similar to that shown previously for the typical summer day. The TES system has the capacity to charge for the full 24 hour run as tank levels go from $30 \%$ to $57 \%$, shown in Figure 25. Similar results have been obtained for a variety of load profiles with varying levels of renewable resources [16].

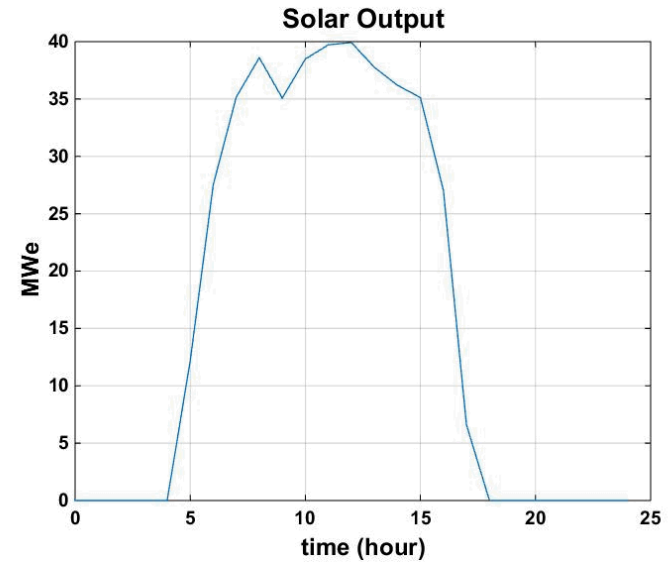

Figure 20: Typical Solar Output for a Summer Day

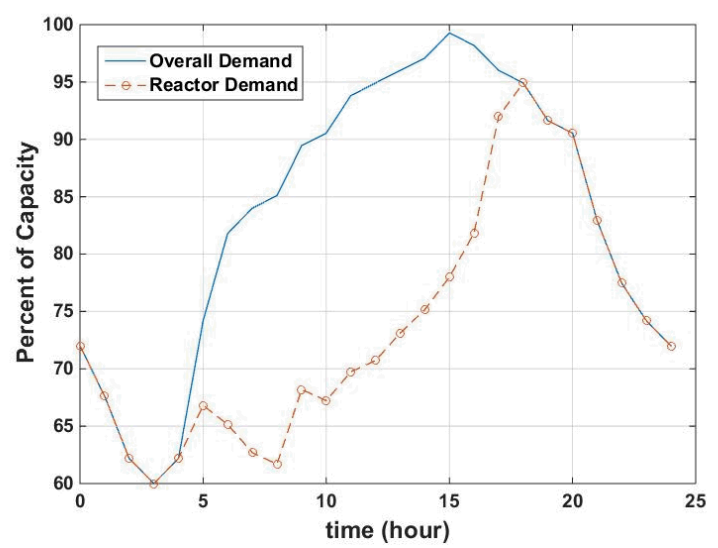

Figure 21: Demand Profiles of a Typical Summer Day with and without Solar 


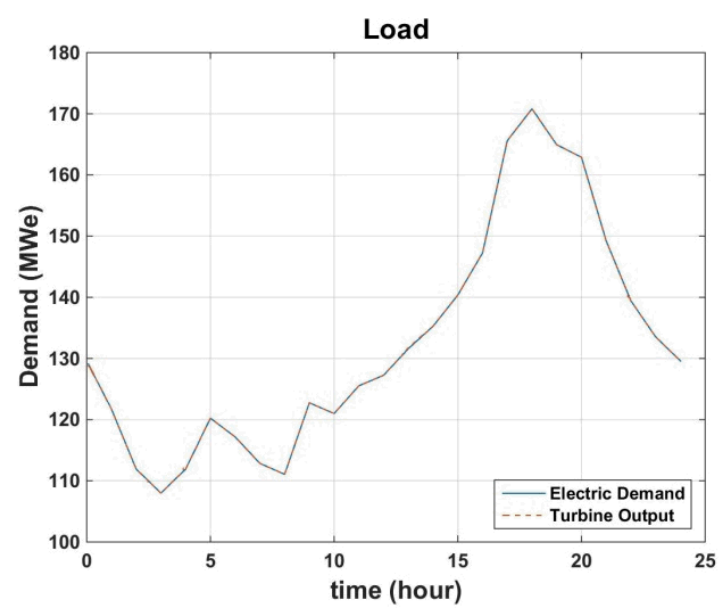

Figure 22: Turbine Load and Output

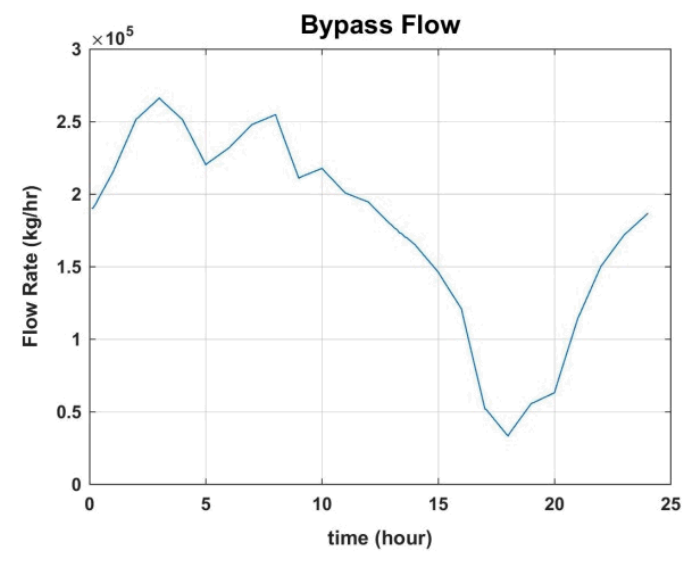

Figure 24: Auxiliary Bypass Flow

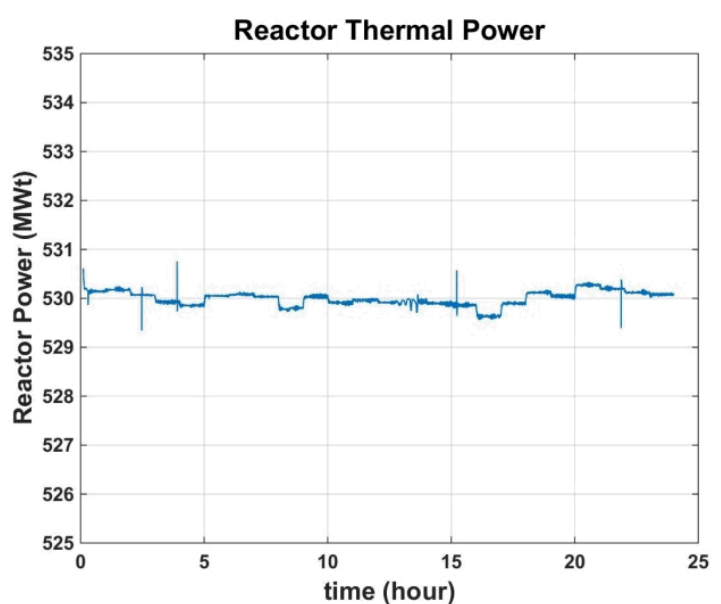

Figure 23: Reactor Power

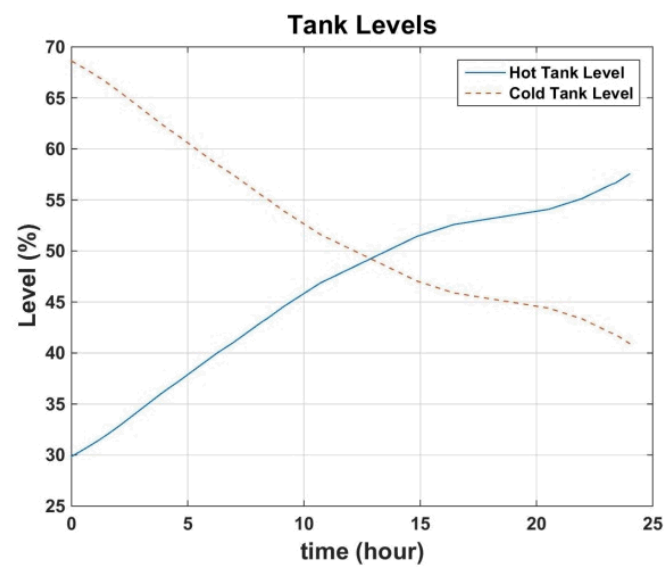

Figure 25: Hot and Cold Tank Levels

\section{III.D. Reactor coupled with Absorption Chillers and Chilled-Water Storage}

When connected to the grid, the electric demand governs the plant turbine output. The control strategy employed by the SMR uses the TCVs to maintain constant pressure in the steam generators, and the control rods move to satisfy some programmed average primary coolant temperature. Ultimately, the control scheme seeks to match turbine output with demand. As the demand drops during off-peak hours, the feed control valves close to match turbine output and demand, and the TCVs close to maintain 
constant steam generator pressure. The TCVs in a more closed position cause the turbine impulse pressure and pressure at all subsequent turbine taps to drop. Lower steam pressure corresponds to a lower steam saturation temperature available to the chillers. Likewise, a smaller pressure difference between the reactor condenser pressure and turbine tap pressure gives rise to less of a driving force for inducing steam flow. Finally, lower steam pressures result in large steam specific volumes which further lessens steam mass flow rates to the absorption chillers. These three factors combined with steam qualities around $85 \%$ downstream of the TES TBV contribute to the absorption chillers running at reduced capacities at lower turbine loads, as illustrated in Figure 26 and 27 [30].

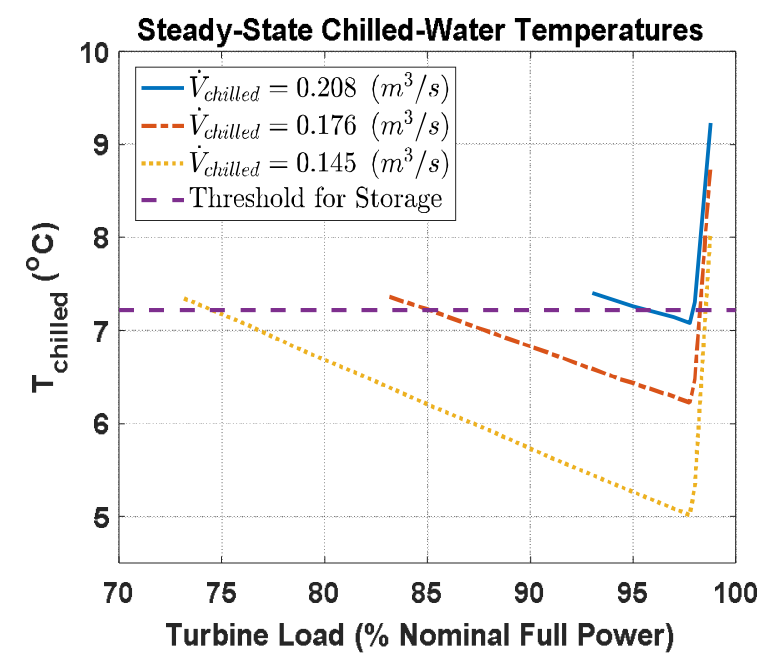

Figure 26: Chilled-water temperature vs. turbine output

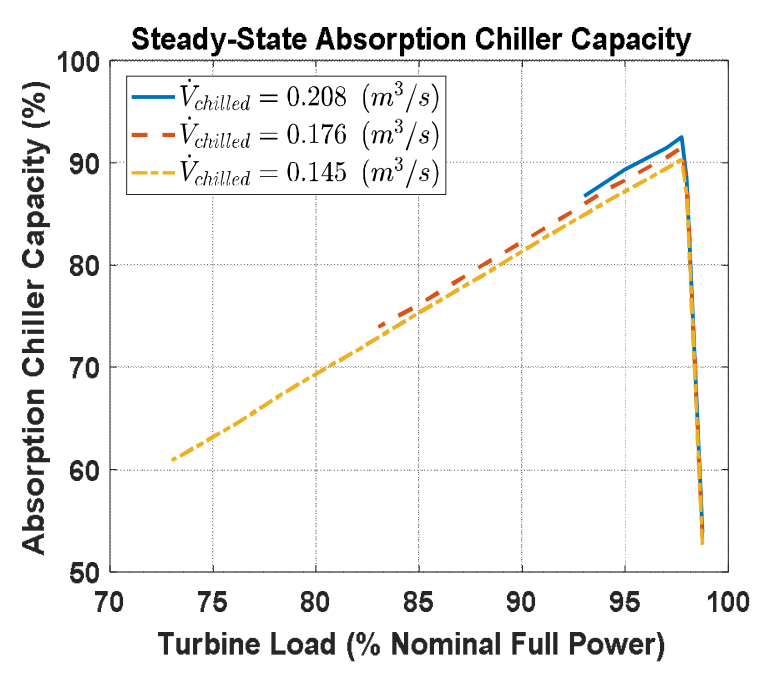

Figure 27: Absorption chiller capacity vs. turbine output

For a constant chilled-water flow rate and constant ambient conditions, the absorption chillers are capable of producing chilled water below the $7.2^{\circ} \mathrm{C}$ temperature threshold for small bands of turbine load. High turbine loads cause the TES TBV to remain closed or partially open. Slightly lower turbine loads cause the TES TBV to fully open. A further reduction in turbine load causes the absorption chiller capacity to reduce more as tap pressure drops. This is counter to the desired effect whereby a reduced turbine (electric) output would result in more chilled water produced. Slower chilled-water flow rates can increase the size of these bands in which the chillers are capable of producing chilled water that is cold enough. However, slower chilled-water flow rates result in long storage tank charging times. Increased 
tank charging times decreases stratification as there is more time for mass diffusion and conduction across the thermocline. Moreover, slower chilled-water flow rates further reduce chiller capacity. Finally, exceptionally slow-chilled water flow rates decrease heat transfer coefficients and make the shell-side refrigerant in the evaporator (water) more susceptible to freezing.

\section{III.E. Absorption Chillers coupled to Flash Vessel Model}

Simulation results [30] reveal that bypassing steam from the low-pressure turbine to three single effect, lithium bromide absorption chillers during periods of excess reactor capacity is not an ideal configuration for shedding load and meeting HVAC requirements given the relative size of the mPower reactor and the load profiles considered here. An alternative configuration involves using the low-grade waste heat coming from the two tank TES system. The TES system maintains reactor power, meets

demand, and stores the excess capacity as shown in Figures 12-25. These dynamics remain unchanged with the addition of the absorption chillers. However, the large amount of waste condensate coming from the sensible heat storage system is perfect for absorption chillers. In response to these findings, this section explores coupling the chilled-water storage system to the flash vessel model. This configuration has several benefits over the low-pressure turbine tap absorption chiller configuration described above. Specifically, the flash vessel system enables use of condensate that would normally be dumped to the condenser. In addition, the various pressure control valves in Figure 5 modulate to maintain steam pressure sent to the chillers roughly constant, thereby ensuring more ideal absorption chiller operation. Like before, absorption chillers are used in conjunction with a stratified chilled-water storage tank to offset cooling loads appropriate for an office space. Typical Meteorological Year (TMY) data is included in the model for cooling tower calculations. The electric demand is the same as the load profile depicted in Figure 12 for a typical summer day. Further simulation details are available in Table IV. 


\section{Table IV. Simulation Parameters}

\begin{tabular}{|l|l|}
\hline Parameter & Value \\
\hline Number of $4,843 \mathrm{~kW}$ absorption chillers & 4 \\
\hline Stratified chilled-water storage tank capacity & $18,827 \mathrm{~m}^{3}(5,000,000$ gallons $)$ \\
\hline Size of conditioned office space & $92,903 \mathrm{~m}^{2}\left(1,000,000 \mathrm{ft}^{2}\right)$ \\
\hline Evaporator flow rate & $0.208 \mathrm{~m}^{3} / \mathrm{s}(3,305 \mathrm{gpm})$ \\
\hline Condenser flow rate & $0.31248 \mathrm{~m}^{3} / \mathrm{s}(4,960 \mathrm{gpm})$ \\
\hline Number of $3,407 \mathrm{~kW}$ cooling towers & 13 \\
\hline Chiller valve open setpoint & Tank below $23 \%$ \\
\hline Chiller valve close setpoint & Tank above $97 \%$ \\
\hline Flash vessel volume & $3,398 \mathrm{~m}^{3}\left(120,000 \mathrm{ft}^{3}\right)$ \\
\hline Flash vessel condensate level setpoint & $3.353 \mathrm{~m}(11 \mathrm{ft})$ \\
\hline $\mathrm{PCV}_{1} ; \mathrm{PCV}_{2} ; \mathrm{PCV}_{3} ; \mathrm{PCV}_{4}$ setpoint & $241 ; 241 ; 248 ; 255 \mathrm{kPa}(35 ; 36 ; 36 ; 37 \mathrm{psia})$ \\
\hline $\mathrm{P}_{\text {impulse2 }}$ setpoint & $212 \mathrm{kPa}(30.7 \mathrm{psia})$ \\
\hline $\mathrm{P}_{\text {chiller }}$ Setpoint & $193 \mathrm{kPa}(28 \mathrm{psia})$ \\
\hline
\end{tabular}

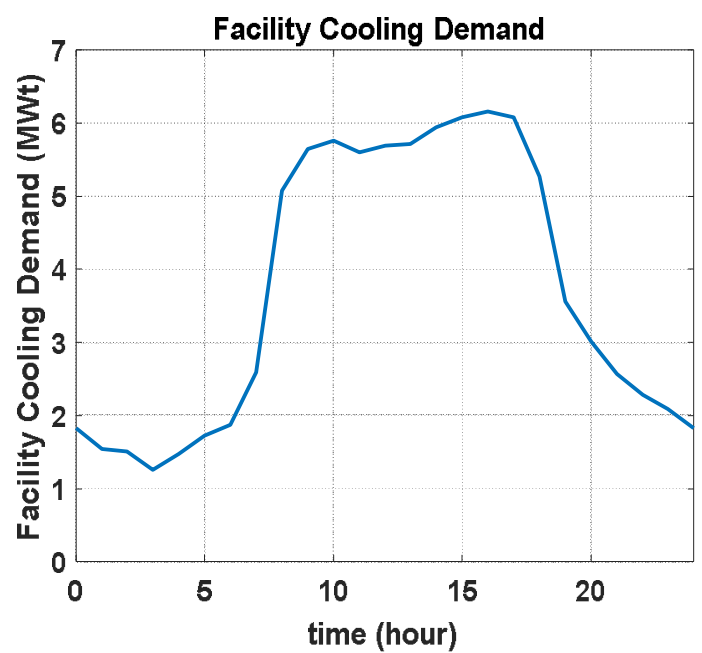

Figure 28. Facility cooling demand

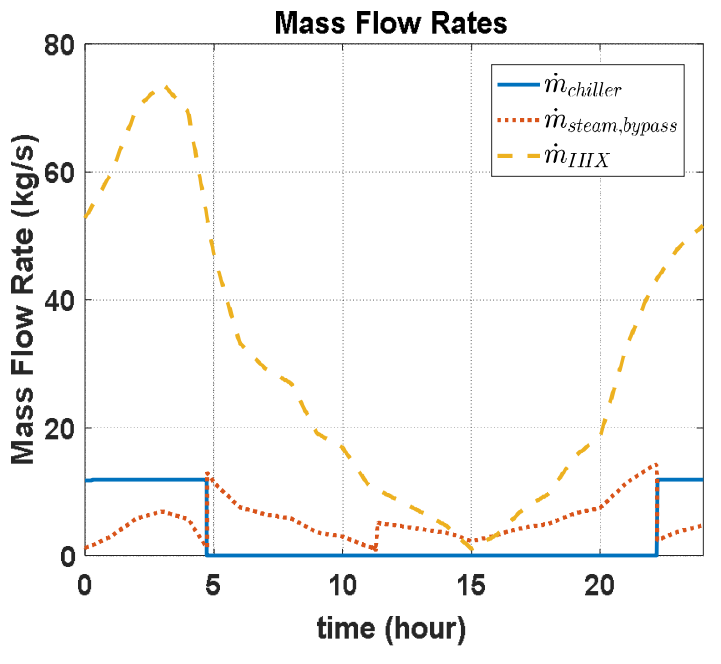

Figure 29. Mass flow rates 


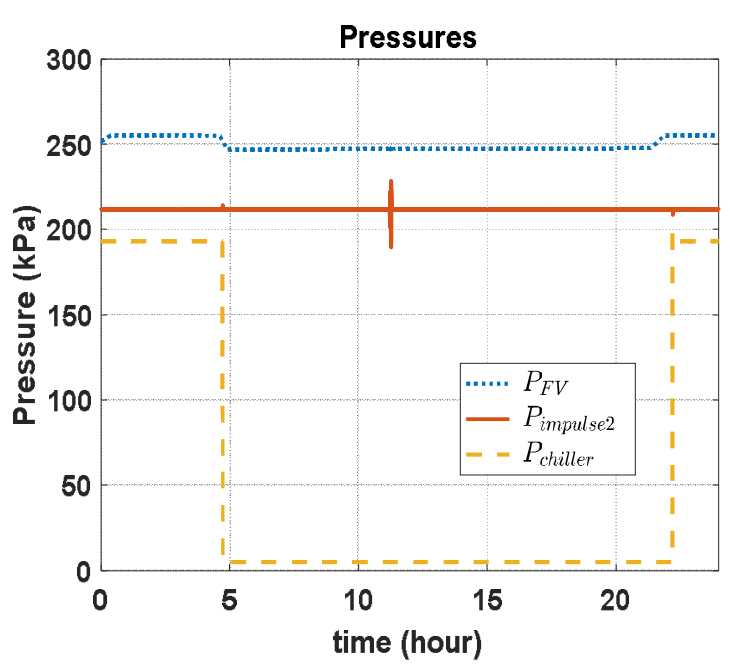

Figure 30. Flash vessel system pressures

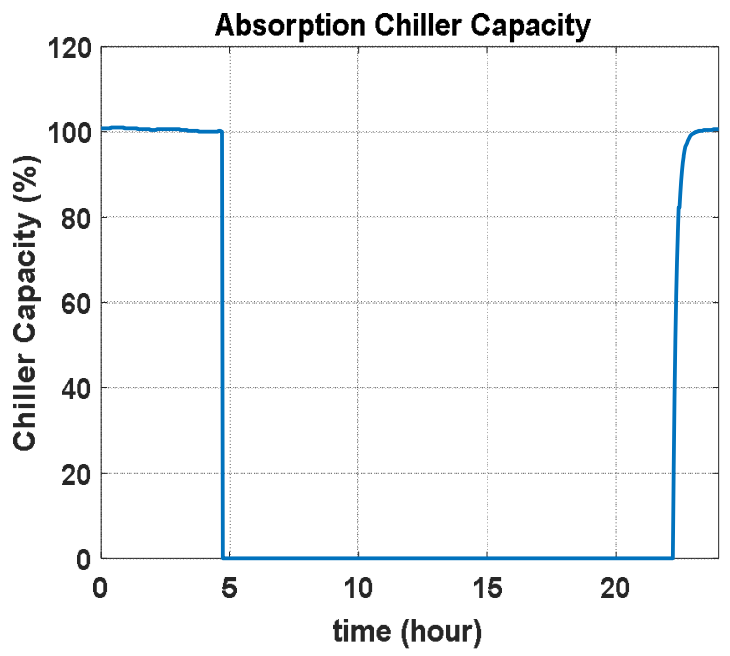

Figure 32. Absorption chiller capacity

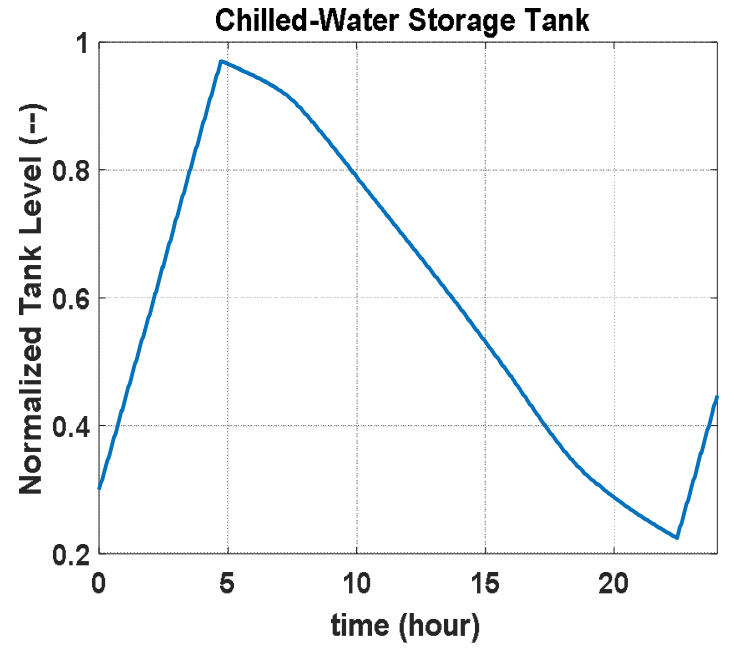

Figure 31. Stratified chilled-water storage tank level

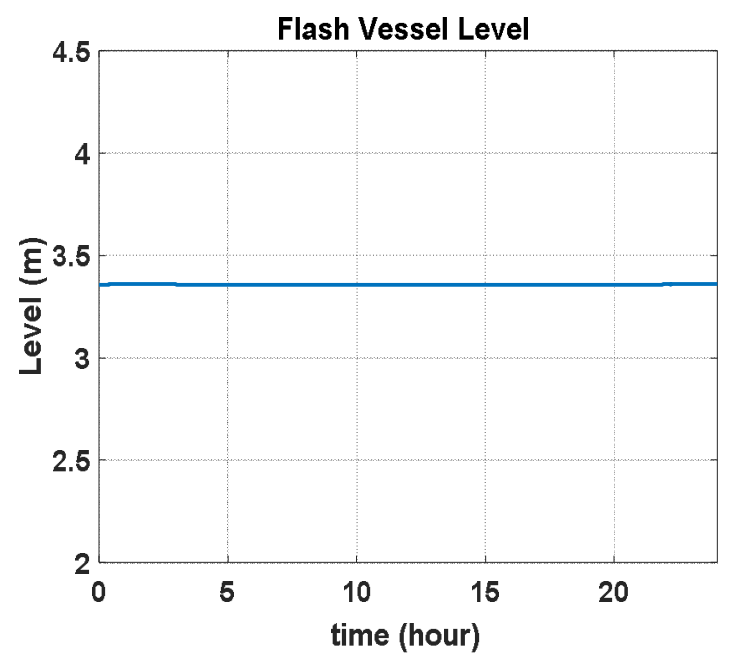

Figure 33. Condensate level in flash vessel

Dynamic simulation results are depicted in Figure 28 through 33. The simulations begin at midnight. The amount of mass flow into the flash vessel is governed by the operation of the ACV in the condensate line between the IHX and the flash vessel. The ACV modulates to maintain condensate level in the IHX hotwell constant. Therefore, the condensate mass flow rate to the flash vessel, shown in Figure 29 , is roughly the x-axis inverse of the electric demand curve illustrated in Figure 12, and a maximum 
during periods of low electric demand. The bank of four pressure control valves move based on their specific pressure setpoints in order to keep pressure in the flash vessel approximately constant. Each pressure control valve in the bank of four leaving the flash vessel is equipped with a unique setpoint, provided in Table IV. This control strategy enables the pressure in the flash vessel to stay roughly constant over the course of the simulation, as depicted in Figure 30. Meanwhile, Figure 33 shows that the LCV successfully modulates to maintain a fixed level of condensate in the flash vessel.

The success of the control strategies surrounding the flash vessel model enables near constant pressure steam to be delivered to the absorption chillers. As a result, the absorption chillers are able to achieve capacities in excess of $100 \%$, as shown in Figure 32. High absorption chiller capacities mean that reduced chilled-water flow rates are not necessary in order to chill the water below the $7.2^{\circ} \mathrm{C}$ temperature threshold for storage and satisfying local facility cooling loads. The use of nominal chilled-water flow rates is twofold: the stratified chilled-water storage tank can be charged faster, and tank losses from mass and temperature diffusion across the thermocline are reduced at higher inlet and outlet storage tank flow rates. Lastly, four absorption chillers can consume a significant portion of the steam produced from flashing the high-pressure condensate in the flash vessel. Once the storage tank becomes full, the absorption chillers are ramped down, and chilled-water in the tank is sent to the facility to satisfy HVAC loads. When the level in the tank falls below its lower setpoint, the chiller valve opens, the absorption chillers warmup, and chilled water is sent to the tank for storage. Unlike the low-pressure turbine tap configuration, the absorption chillers achieve nominal capacities during times of excess reactor capacity. Results depicted in the above figures demonstrate the ability to maintain the reactor thermal output at $100 \%$ and match turbine output with an electric demand profile characteristic of a typical summer day down to $60 \%$ load, while simultaneously using four large absorption chillers to charge a $18,927 \mathrm{~m}^{3}$ stratified chilled-water storage tank to offset HVAC loads of an adjacent office space. 


\section{Conclusions}

The results presented demonstrate the feasibility of using TES systems coupled to Small Modular Reactors to minimize power swings during periods of variable electric load. If SMRs are to be deployed in conjunction with intermittent power sources such as wind and solar, these load variations can be significant. Current SMR designs allow for bypass off the pressure equalization header prior to the pressure control valves thus providing approximately constant steam conditions perfect for sensible heating thermal energy storage systems. Using a two-tank sensible heat storage system, it has been shown thermal energy can be stored during periods of low demand, to be recovered in the future for either electric generation or process heat applications.

Furthermore, it has been shown that the addition of a sensible heat storage system provides a source of high pressure, low grade heat that can be utilized for other process steam applications such as chilled-water production and storage. The additional ancillary applications increase the overall efficiency of the system making the system more beneficial from an economic standpoint.

With the implementation of these TES systems, decreases in capacity factor and increased stresses on plant components associated with load follow operation can be minimized, improving economic return over the lifespan of the reactor. 


$\begin{array}{ll}\text { Nomenclature } & \\ \text { ACV } & \text { auxiliary control valve } \\ \text { Aux } & \text { auxiliary } \\ \text { CHP } & \text { combined heat and power } \\ \text { FBV } & \text { feed bypass valve } \\ \text { FCV } & \text { flow control valve } \\ \text { FDCV } & \text { feed control valve } \\ \text { FV } & \text { flash vessel } \\ \text { HVAC } & \text { heating ventilation and air conditioning } \\ \text { IHX } & \text { intermediate heat exchanger } \\ \text { IPWR } & \text { integral pressurized water reactor } \\ \text { LCV } & \text { level control valve } \\ \text { MWe } & \text { megawatts electric } \\ \text { MWt } & \text { megawatts thermal } \\ \text { NHES } & \text { nuclear hybrid energy system } \\ \text { OTSG } & \text { once through steam generator } \\ \text { PCV } & \text { pressure control valve } \\ \text { PRV } & \text { pressure relief valve } \\ \text { PV } & \text { photovoltaic } \\ \text { SMR } & \text { small modular reactor } \\ \text { TBV } & \text { turbine bypass valve } \\ \text { TCV } & \text { turbine control valve } \\ \text { TES } & \text { thermal energy storage } \\ & \end{array}$




\section{References}

1. "Electricity Explained: Electricity in the United States," http://www.eia.gov/energyexplained/index.cfm?page=electricity_in_the_united_states (2016).

2. F. Aydogan, G. Black, M. A. T. Black, and D. Solan, "Quantitative and Qualitative Comparison of Light Water and Advanced Small Modular Reactors," ASME J. Nucl. Eng. Radiat. Sci., 1, pp.041001$1-14$.

3. "Small Modular Reactors (SMRs)," http://www.energy.gov/ne/nuclear-reactor-technologies/smallmodular-nuclear-reactors (2017).

4. D. INGERSOLL, C. COLBERT, Z. HOUGHTON, R. SNUGGERUD, J. GASTON, and M. EMPEY. "Can Nuclear Power and Renewables Be Friends?" Proceedings of ICAPP (2015): 3129-3137. Print.

5. S. BRAGG-SITTON, R. BOARDMAN, J. COLLINS, M. RUTH, O. ZINAMAN, C. FORSBERG. "Integrated Nuclear-Renewable Energy Systems: Foundational Workshop Report". Idaho National Laboratory, INL/EXT-14-32857 Rev. 1 (2014).

6. K. POWELL, T. EDGAR. "Modeling and control of a solar thermal power plant with thermal energy storage”. Chemical Engineering Science. 138-145, 71 (2012).

7. Advances in Small Modular Reactor Technology Developments; A supplement to IAEA Advanced Reactors Information System (ARIS), IAEA (2014)

8. H. Shen, "Advanced Feedwater Control for Next Generation Nuclear Power Systems," PhD Thesis, Nuclear Engineering Department, North Carolina State University, (2006).

9. Alan S. Rominger and J. Michael Doster , "Fast Valving for Small and Medium Sized Reactors", Proceedings of the $7^{\text {th }}$ International Topical Meeting on Nuclear Plant Instrumentation, Control and Human Machine Interface Technologies (NPIC\&HMIT 2010) Las Vegas, Nevada, November 2010

10. Alan S. Rominger and J. Michael Doster, "Benefits of Small Modular Reactors for Challenging Electric Grid Operation", Proceedings of the $8^{\text {th }}$ International Topical Meeting on Nuclear Plant Instrumentation, Control and Human Machine Interface Technologies (NPIC\&HMIT 2012) San Diego, CA, July, 2012

11. Andrew J. Petrarca and J. Michael Doster, "Low Power Feedwater Control in Helical Steam Generators", Proceedings of the $8^{\text {th }}$ International Topical Meeting on Nuclear Plant Instrumentation, Control and Human Machine Interface Technologies (NPIC\&HMIT 2012) San Diego, CA, July, 2012

12. Sohal, M. S., Ebner, M. A., Sabharwall, P., \& Sharpe, P. (March 2010). Engineering Database of Liquid Salt Thermophysical and Thermochemical Properties. Idaho National Laboratory. INL/Ext-1018297

13. Solutia: Applied Chemistry, Creative Solutions, Therminol 66: High Performance Highly Stable Heat Transfer Fluid.

14. Solutia: Applied Chemistry, Creative Solutions, Therminol 68: Highly Stable Low Viscosity Heat Transfer Fluid.

15. Solutia, Therminol 75: Synthetic, Aromatic, High-temperature Heat Transfer Fluid. 
16. K. Frick, Coupling and Design of a Thermal Energy Storage System for Small Modular Reactors, Masters of Science Thesis, Department of Nuclear Engineering, North Carolina State University, 2016.

17. R. K. Suri, A. M. R. Al-Marafie, G. P. Maheshwari, F. Al-Juwayadal, S. Al-Jandal, K. Al-Madani, and H. Aburshaid, "Experimental Investigation of Chilled-Water Storage Technique for Peak Power Shaving," Int. J. Refrig., 12, pp.213-219.

18. A. M. R. Al-Marafie, "Stratification Behaviour in a Chilled-Water Storage Tank," Int. J. Refrig., 10, pp. 213-219 (1987).

19. C. T. Misenheimer and S. D. Terry, "Modeling Hybrid Nuclear Systems with Chilled-Water Storage," ASME J. Energy Resourc. Technol., 139, (2016).

20. K. E. Herold, R. Radermacher, and S. A. Klein, Absorption Chillers and Heat Pumps, CRC Press, Boca Raton, FL (2016).

21. O. Marc, F. Sinama, J. P. Praene, F. Lucas, and J. Castaing-Lasvignottes, "Dynamic modeling and experimental validation elements of a $30 \mathrm{~kW} \mathrm{LiBr} / \mathrm{H} 2 \mathrm{O}$ single effect absorption chiller for solar application," Applied Thermal Engineering, 90, pp.980-993 (2015).

22. G. Evola, N. Le Pierres, F. Boudehenn, and P. Papillon, "Proposal and Validation of a Model for the Dynamic Simulation of a Solar-Assisted Single-Stage LiBr/Water Absorption Chiller, ” Int. J. Refrig., 36, pp.1015-1028 (2013).

23. W. M. Rohsenow, J. P. Hartnett, and Y. I. Cho, Handbook of Heat Transfer, McGraw-Hill, New York, USA (1998).

24. F. Cosenza and G. C. Vliet, "Absorption in Falling Water/LiBr Films on Horizontal Tubes," ASHRAE Transactions, 96, pp.693-701 (1990).

25. M. K. Dobson and J. C. Chato, "Condensation in Smooth Horizontal Tubes," ASME Journal of Heat Transfer, 120, pp.193-213 (1998).

26. L. Friedel, "Improved Friction Pressure Drop Correlation for Horizontal and Vertical Two-phase Pipe Flow," Proceedings of the European Two-phase Flow Group Meeting, Ispra, Italy, paper E2 (1979).

27. C. T. Misenheimer and S. D. Terry, "The development of a Dynamic, Single Effect, Lithium Bromide Absorption Chiller Model with Enhanced Generator Fidelity," Energy Conversion and Management, 150, pp.574-587 (2017).

28. C. T. Misenheimer, Modeling Chilled-Water Storage System Components for Coupling to a Small Modular Reactor in a Nuclear Hybrid Energy System, Doctoral Dissertation, Department of Mechanical and Aerospace Engineering, North Carolina State University, 2017.

29. "Renewable Energy and Electricity," 20 June 2016. [Online]. Available:

http://www.worldnuclear.org/information-library/energy-and-the-environment/renewable-energy-andelectricity.aspx. [Accessed 08 July 2016].

30. C. Misenheimer, S. Terry, J.M. Doster and S. Bragg-Sitton, "Analysis of a Nuclear Hyrbid Energy System using Absorption Chillers and Stratified Chilled-Water Storage with an mPower Reactor," in 
10th International Topical Meeting on Nuclear Plant Instrumentation, Control and Human Machine Interface Technologies, San Francisco, CA, 2017. 